\title{
Extremely Elevated Procalcitonin in a Case of Acetaminophen Overdose and Acute Liver Injury
}

\author{
Yoshito Nishimura ${ }^{1}$, Jakrin Kewcharoen ${ }^{1}$ and Toni Narimasu ${ }^{2}$
}

\begin{abstract}
:
We herein report a 46-year-old man who suffered an intentional acetaminophen overdose. Laboratory results revealed leukocytosis and an elevated procalcitonin level $(8.48 \mathrm{ng} / \mathrm{mL})$. Computed tomography showed findings suggesting possible colitis. Due to concerns about sepsis in addition to acetaminophen overdose, oral $\mathrm{N}$-acetyl cysteine and piperacillin/tazobactam were started. His procalcitonin levels further increased; however, the patient remained afebrile, and the C-reactive protein levels were normal. Piperacillin/tazobactam was discontinued, and he remained stable without antibiotics. The present case shows that the toxicokinetics of acetaminophen overdose can cause an elevated procalcitonin level. Furthermore, procalcitonin levels alone should not guide the need for antibiotics in such cases.
\end{abstract}

Key words: acetaminophen, overdose, procalcitonin, acute liver injury

(Intern Med Advance Publication)

(DOI: 10.2169/internalmedicine.7192-21)

\section{Introduction}

Acetaminophen is an analgesic and antipyretic commonly used by millions of people, with over 600 marketed products, including over-the-counter (OTC) drugs. Given its popularity, acetaminophen overdose is the most common cause of drug-induced acute liver injury in the United States (1), and intentional acetaminophen overdose is often cited as a common suicidal activity (2).

Patients with acetaminophen overdose often have nonspecific symptoms, such as generalized weakness, abdominal pain, and nausea. While acetaminophen-induced liver injury is considered to occur in a dose-dependent fashion, those who overdose with relatively low-dose acetaminophen over several days may still suffer liver toxicity. The serum aminotransferase levels on admission are frequently within normal limits but may rapidly increase within $24 \mathrm{~h}$ after hospitalization (3). The standard treatment for acetaminophen overdose is $\mathrm{N}$-acetyl cysteine administration, which effectively mitigates liver injury if administered early (4).

Procalcitonin (PCT), an active precursor of calcitonin, is associated with the response to bacterial infection (5). Despite its usefulness for guiding antibiotic therapy in cases of severe infection, such as sepsis (6-8), dependence on PCT to diagnose sepsis has been the subject of debate over the past several years $(9,10)$.

We herein report a case of intentional acetaminophen overdose in a patient with a significantly elevated PCT level. While the patient received antibiotics initially, the medical team ruled out sepsis following an observation period. The elevated PCT level was considered to be acetaminopheninduced. This case shows that acetaminophen overdose can significantly increase PCT levels and mimic sepsis, resulting in unnecessary antibiotic use.

\section{Case}

A 46-year-old Vietnamese man with a relevant medical history of schizophrenia, recurrent suicidal ideation (SI), hypertension (HTN), and insulin-dependent diabetes type 2 (IDDM2) presented to the emergency department (ED) with an altered mental status and SI. According to the patient, he had been in his usual state of health until 4 days prior to the ED visit, when he began to have SI and ingested large

${ }^{1}$ Department of Medicine, John A. Burns School of Medicine, University of Hawai'i, USA and ${ }^{2}$ Hospitalist Program, Queen's Medical Center, USA

Received: January 31, 2021; Accepted: May 10, 2021; Advance Publication by J-STAGE: June 26, 2021

Correspondence to Dr. Yoshito Nishimura, yoshiton@ @awaii.edu 
Table 1. Laboratory Results on Admission.

\begin{tabular}{lcc}
\hline \multicolumn{1}{c}{ Parameter } & Value & (Reference range)/units \\
\hline WBC & 20,000 & $(3,800-10,800) / \mu \mathrm{L}$ \\
Hemoglobin & 16.6 & $(13.7-17.5) \mathrm{g} / \mathrm{dL}$ \\
Platelet & 304 & $\left(151-424 \times 10^{3}\right) / \mu \mathrm{L}$ \\
Sodium & 136 & $(133-145) \mathrm{mEq} / \mathrm{L}$ \\
Potassium & 3.3 & $(3.3-5.1) \mathrm{mEq} / \mathrm{L}$ \\
Chloride & 95 & $(95-108) \mathrm{mEq} / \mathrm{L}$ \\
Calcium & 10.1 & $(8.3-10.5) \mathrm{mg} / \mathrm{dL}$ \\
BUN & 17 & $(6-23) \mathrm{mg} / \mathrm{dL}$ \\
Creatinine & 1.3 & $(0.6-1.4) \mathrm{mg} / \mathrm{dL}$ \\
AST & 24 & $(0-40) \mathrm{IU} / \mathrm{L}$ \\
ALT & 42 & $(0-41) \mathrm{IU} / \mathrm{L}$ \\
ALP & 120 & $(35-129) \mathrm{IU} / \mathrm{L}$ \\
Total bilirubin & 0.6 & $(0-1.2) \mathrm{mg} / \mathrm{dL}$ \\
Total protein & 9.4 & $(6.4-8.3) \mathrm{g} / \mathrm{dL}$ \\
Albumin & 5.4 & $(3.5-5.2) \mathrm{g} / \mathrm{dL}$ \\
PT-INR & 1.1 & \\
Procalcitonin & 8.48 & $(<0.05) \mathrm{ng} / \mathrm{mL}$ \\
Lactate & 5.9 & $(0.5-2.2) \mathrm{mEq} / \mathrm{L}$ \\
Acetaminophen & 75 & $(10-30) \mu \mathrm{g} / \mathrm{mL}$ \\
\hline
\end{tabular}

ALP: alkaline phosphatase, ALT: alanine transaminase, AST: aspartate transaminase, BUN: blood urea nitrogen, PT-INR: prothrombin time of the international normalized ratio, WBC: white blood cell

amounts of over-the-counter (OTC) acetaminophen tablets. He mentioned having taken approximately 15 tabs of a 325$\mathrm{mg}$ formula (about $4.9 \mathrm{~g}$ of acetaminophen) every day for the past 4 days. He denied any recent use of alcohol or other illicit drugs, including methamphetamine, marijuana, or benzodiazepines. He was brought to the ED by his family after admitting taking acetaminophen in a suicide attempt.

The patient had diffuse abdominal pain without radiation, associated with nausea and watery diarrhea. His medical history was significant for HTN, IDDM2, chronic kidney disease (CKD) stage 3a, a history of right post-capsular ischemic stroke, schizophrenia, anxiety disorder, and polysubstance abuse, including benzodiazepines and methamphetamine. His daily medications were significant for multiple psychiatric drugs, including Aripiprazole, Sertraline, and Trazodone.

Upon presentation, he was hypertensive with a blood pressure of 159/103 mmHg, pulse rate of 84 beats per minute, and no fever. He was lethargic and irritable and was unable to provide a reliable history. No scleral icterus was noted. There was left upper quadrant tenderness without guarding on an abdominal examination. On a neurological examination, his cranial nerves were grossly intact without focal deficits. The results of initial laboratory investigations are summarized in Table 1. On admission, the white blood cell (WBC) count was $20,000 / \mu \mathrm{L}$ with a neutrophil predominance $(86.9 \%)$. The basic metabolic panel, liver function tests (LFTs), coagulation studies, and urinalysis findings were grossly normal. His serum acetaminophen level was elevated to $75 \mu \mathrm{g} / \mathrm{mL}$ (reference range: $10-30 \mu \mathrm{g} / \mathrm{mL}$ ), while serum ethanol and urine toxicology findings were negative. However, his PCT and lactic acid levels were significantly elevated at $8.48 \mathrm{ng} / \mathrm{mL}$ (reference range: $<0.05 \mathrm{ng} / \mathrm{mL}$ ) and $5.9 \mathrm{mEq} / \mathrm{L}$ (reference range: $0.5-2.2 \mathrm{mEq} / \mathrm{L}$ ), respectively.

These findings raised concerns about sepsis and prompted further diagnostics, including chest X-ray and contrastenhanced computed tomography (CT) from the abdomen to the pelvis, given his reported gastrointestinal symptoms. Chest X-ray showed no cardiomegaly or new infiltrates, but CT revealed fluid-filled loops of bowel associated with colonic wall thickening, suggesting possible enterocolitis. No hepatic abscess, choledocholithiasis, or urinary tract obstruction noted.

Given his clinical presentation, leukocytosis with an extremely elevated PCT level, and the CT findings, empiric treatment for both acetaminophen overdose and sepsis secondary to possible bacterial enterocolitis were started. For the acetaminophen overdose, he was immediately started on a 72-h course with oral N-acetyl cysteine (NAC) $(70 \mathrm{mg} / \mathrm{kg}$ every $4 \mathrm{~h}$ for 17 doses). For sepsis, the patient was given piperacillin/tazobactam (PIPC/TAZ) $4.5 \mathrm{~g}$ every $6 \mathrm{~h}$ after two sets of blood cultures were collected.

Table 2 summarizes the trends in WBCs, LFTs, PCT levels, and other relevant laboratory results during hospitalization. While his gastrointestinal symptoms had resolved and remained clinically stable without a fever, his PCT level had risen to $31.29 \mathrm{ng} / \mathrm{mL}$ on hospital day 3. However, his Creactive protein $(\mathrm{CRP})$ level on the same day was within normal limits $(0.93 \mathrm{mg} / \mathrm{dL}$; reference range: $0.0-1.0 \mathrm{mg} / \mathrm{dL})$, and his WBC count continued to show a decreasing trend. Given the isolated elevation in his PCT level, underlying sepsis was deemed unlikely, and PIPC/TAZ was discontinued. This WBC count continued to normalize after discontinuation of the antibiotics, and he remained afebrile. The final result of blood cultures obtained on admission was negative. Liver enzyme levels peaked on hospital day 4, requiring an extension of oral NAC therapy. Due to persistent SI, he was transferred to the inpatient psychiatric unit on hospital day 5 .

\section{Discussion}

Serum PCT has become a standard laboratory test performed in daily practice. While PCT might be useful for diagnosing sepsis or reducing the duration of antibiotic therapy in some cases of bacterial infections $(5-9,11)$, previous studies have reported that the PCT level is also increased in other disorders, including shock, trauma, hepatic or renal failure, malignancy, and some autoimmune disorders $(11,12)$. As in the present case with a significantly elevated PCT level $(31.29 \mathrm{ng} / \mathrm{mL})$, a few case reports have also noted that patients with acute liver failure due to acetaminophen intoxication without infection had high PCT levels (13-15). Our patient had increased PCT levels ahead of AST and ALT elevation, which might have been due to the relatively rapid induction time of PCT (about two to four 
Table 2. Trends of Creatine Kinase, Creatinine, and Liver Function Tests.

\begin{tabular}{lccccccc}
\hline Parameter & Day 1 & Day 2 & Day 3 & Day 4 & Day 5 & Day 6 & (Reference range)/units \\
\hline WBC & 20,000 & 23,610 & 12,130 & 11,320 & 10,350 & & $(3,800-10,800) / \mu \mathrm{L}$ \\
PCT & 8.48 & & 31.29 & 13.54 & & & $(<0.05) \mathrm{ng} / \mathrm{mL}$ \\
CRP & & & 0.93 & & & & $(0.0-1.0) \mathrm{mg} / \mathrm{dL}$ \\
AST & 24 & 17 & 65 & 484 & 190 & 73 & $(0-40) \mathrm{IU} / \mathrm{L}$ \\
ALT & 42 & 33 & 69 & 520 & 500 & 359 & $(0-41) \mathrm{IU} / \mathrm{L}$ \\
\hline
\end{tabular}

ALT: alanine transaminase, AST: aspartate transaminase, BUN: blood urea nitrogen, CRP: C-reactive protein, PCT: procalcitonin, WBC: white blood cell

Table 3. Summary of Adult Cases with Acetaminophen Toxicity who Had Elevated Procalcitonin.

\begin{tabular}{lcccccccc}
\hline Case & Ref & $\begin{array}{c}\text { Age/ } \\
\text { Sex }\end{array}$ & $\begin{array}{c}\text { Total } \\
\text { Acetaminophen } \\
\text { Dose }(\mathrm{mg})\end{array}$ & $\begin{array}{c}\text { Acetaminophen } \\
\text { Concentration } \\
(\mu \mathrm{g} / \mathrm{mL})\end{array}$ & $\begin{array}{c}\text { PCT } \\
(\mathrm{ng} / \mathrm{mL})\end{array}$ & $\begin{array}{c}\text { CRP } \\
(\mathrm{mg} / \mathrm{dL})\end{array}$ & $\begin{array}{c}\text { AST } \\
(\mathrm{IU} / \mathrm{L})\end{array}$ & $\begin{array}{c}\text { ALT } \\
(\mathrm{IU} / \mathrm{L})\end{array}$ \\
\hline 1 & 14 & $24 / \mathrm{F}$ & 8,000 & $<0.5$ & 31.89 & $<0.05$ & 20 & 11 \\
2 & 14 & $51 / \mathrm{M}$ & 23,600 & 116.9 & 45.66 & 0.18 & 2,508 & 1,473 \\
3 & 15 & $65 /-$ & 20,000 & 162.4 & 23.15 & $<0.03$ & 11,939 & 6,988 \\
4 & 15 & $34 /-$ & 38,000 & 149.6 & 79.78 & $<0.03$ & N/A & 18 \\
5 & Present case & $46 / \mathrm{M}$ & 19,600 & 75.0 & 31.29 & 0.93 & 484 & 520 \\
\hline
\end{tabular}

The sex of cases 3 and 4 was not specified in the manuscript.

ALT: alanine transaminase, AST: aspartate transaminase, CRP: C-reactive protein, PCT: procalcitonin, Ref: reference

hours after the insults) (11). While the reason why patients with acetaminophen intoxication have markedly elevated PCT levels is unclear, it has been speculated that acetaminophen-induced hepatocyte damage and subsequent activation of inflammasomes may induce interleukin-2 and tumor necrosis factor-alpha release, which leads to PCT release from hepatocytes (14). Further research is needed to clarify the pathophysiology underlying PCT elevation in cases of acetaminophen intoxication, but providers should be aware that extremely elevated PCT levels are not synonymous with sepsis in these cases.

In addition, previous case reports on acetaminophen intoxication without sepsis noted normal or low serum CRP level despite PCT elevation $(14,15)$, which echoes the findings in this case report. Although a previous study showed no significant correlation between serum PCT levels and the clinical prognosis in pediatric patients with acetaminophen toxicity (13), whether or not the extent of PCT elevation correlates with a poor clinical prognosis in adult cases of acetaminophen overdose is still unclear. Future studies should clarify whether or not elevated PCT levels can predict acetaminophen-induced liver injury at an earlier stage, and the discrepancy in serum PCT and CRP levels might be useful in determining if patients have concomitant sepsis with acetaminophen intoxication.

Global health experts have recently noted that antimicrobial resistance (AMR) and stewardship are urgent public health agendas $(16,17)$. While the PCT-guided use of antibiotics is useful in some cases, the utility of the PCT level alone in acetaminophen intoxication as an indicator of sepsis is questionable. The clinical decision on whether or not to start antibiotics with acetaminophen intoxication should be based on a comprehensive assessment of the clinical presentation, which is the gold standard of sepsis, in order to decrease the unnecessary use of antibiotics and reduce the risk of resistant pathogens in the future.

The authors state that they have no Conflict of Interest (COI).

\section{References}

1. Bari K, Fontana RJ. Acetaminophen overdose: What practitioners need to know. Clin Liver Dis (Hoboken) 4: 17-21, 2014.

2. de Achaval S, Suarez-Almazor M. Acetaminophen overdose: a little recognized public health threat. Pharmacoepidemiol Drug Saf 20: 827-829, 2011.

3. Myers RP, Li B, Fong A, Shaheen AA, Quan H. Hospitalizations for acetaminophen overdose: a Canadian population-based study from 1995 to 2004. BMC Public Health 7: 143, 2007.

4. Smilkstein MJ, Knapp GL, Kulig KW, Rumack BH. Efficacy of oral $\mathrm{N}$-acetylcysteine in the treatment of acetaminophen overdose. Analysis of the national multicenter study (1976 to 1985). N Engl J Med 319: 1557-1562, 1988.

5. Simon P, Milbrandt EB, Emlet LL. Procalcitonin-guided antibiotics in severe sepsis. Crit Care 12: 309, 2008.

6. Bouadma L, Luyt CE, Tubach F, Cracco C, Alvarez A, Schwebel $\mathrm{C}$, et al. Use of procalcitonin to reduce patients' exposure to antibiotics in intensive care units (PRORATA trial): a multicentre randomised controlled trial. Lancet 375: 463-474, 2010.

7. Schuetz P, Wirz Y, Sager R, Christ-Crain M, Stolz D, Tamm M, et al. Procalcitonin to initiate or discontinue antibiotics in acute respiratory tract infections. Cochrane Database Syst Rev 10: CD 007498, 2017.

8. Huang DT, Yealy DM, Filbin MR, Brown AM, Chang CH, Doi Y, et al. Procalcitonin-Guided Use of Antibiotics for Lower Respiratory Tract Infection. N Engl J Med 379: 236-249, 2018.

9. Wacker C, Prkno A, Brunkhorst FM, Schlattmann P. Procalcitonin as a diagnostic marker for sepsis: a systematic review and meta- 
analysis. Lancet Infect Dis 13: 426-435, 2013.

10. Rule JA, Hynan LS, Attar N, Sanders C, Korzun WJ, Lee WM, et al. Procalcitonin Identifies Cell Injury, Not Bacterial Infection, in Acute Liver Failure. PLoS One 10: e0138566, 2015.

11. Meisner M. Update on procalcitonin measurements. Ann Lab Med 34: 263-273, 2014.

12. Sugihara T, Koda M, Okamoto T, Miyoshi K, Matono T, Oyama $\mathrm{K}$, et al. Serum Procalcitonin in Patients with Acute Liver Failure. Yonago Acta Med 60: 40-46, 2017.

13. Tschiedel E, Assert R, Felderhoff-Muser U, Kathemann S, Witzke $\mathrm{O}$, Hoyer P, et al. Undue Elevation of Procalcitonin in Pediatric Paracetamol Intoxication is Not Explained by Liver Cell Injury Alone. Ann Hepatol 17: 631-637, 2018.

14. Ahn JH, Cho YS, Cho GC. Elevated procalcitonin levels in patients with acetaminophen intoxication: two case reports: A CARE-compliant article. Medicine (Baltimore) 99: e18882, 2020.
15. García de, Guadiana Romualdo L, Rodríguez Rojas C, Ramos Arenas V, Cárdenas Gámez R, López Abellán MD, González Morales $\mathrm{M}$. Increased concentrations of procalcitonin in patients with paracetamol intoxication. In: Advances in Laboratory Medicine/ Avances en Medicina de Laboratorio. 202001082021.

16. Nishizawa $H$, Nishimura $Y$, Matsumura $H$, Horiuchi $H$, Higashira T, Kita Y, et al. G20 Okayama Health Ministers' Meeting: Conclusions and commitments. J Glob Health 10: 010320, 2020.

17. Matsumura H, Nishimura $Y$, Horiuchi $H$, Higashira $T$, Kita $Y$, Nishizawa H. G20 Okayama Health Ministers' Meeting: lessons learned and way forward. Global Health \& Medicine 1: 65-70, 2019.

The Internal Medicine is an Open Access journal distributed under the Creative Commons Attribution-NonCommercial-NoDerivatives 4.0 International License. To view the details of this license, please visit (https://creativecommons.org/licenses/ by-nc-nd/4.0/).

\section{(C) The Japanese Society of Internal Medicine} Intern Med Advance Publication 